\title{
Performers sem Fronteiras, uma plataforma clínico-performativa de ações em arte relacional
}

\author{
Diogo Rezende, Tânia Alice
}

Universidade Federal do Estado do Rio de Janeiro, Rio de Janeiro, RJ, Brasil

Resumo

\begin{abstract}
O artigo aborda o trabalho da plataforma clínico-performativa Performers sem Fronteiras (PsF), que trabalha em contextos de pessoas em situação de trauma pontual ou crônico, bem como em ações de cultivo e promoção de saúde. Vamos abordar a interface arte/cura a partir do conceito de PARC (Performances de Arte Relacional como prática de Cura), desenvolvido por Tania Alice, em algumas ações clínico-performáticas realizadas pelo conjunto da plataforma, em volta de três eixos norteadores do trabalho do coletivo: 1. O movimento livre como prática clínica pela criação de plataformas pontuais de livre expressão do corpo. 2 . O empoderamento dos participantes, pensado a partir de um trabalho realizado por dois integrantes do PsF junto a usuários da rede de saúde mental do Rio de Janeiro intitulado "Todo sonho bem sonhado pode um dia virar realidade". 3. A potencialização dos afetos dentro da performance "Correio de abraços Brasil/Nepal" de Tania Alice.
\end{abstract}

Palavras-chave: performance; arte relacional; clínica.

\section{Performers without borders, a clinical-performative platform of actions in relational art}

\begin{abstract}
The article discusses the work of the clinical-performative platform Performers without Borders (PsF), which works in contexts of people with punctual or chronic trauma, as well as in actions that cultivate and promote health. We will aproach the art/healing interface based on the concept of PARC (Performances of Relational Art as Cure practice), developed by Tania Alice, in some clinical-performative actions performed by the platform, set around three axes guiding the work of the collective: 1. The free movement as therapeutic practice by the creation of punctual platforms of free expression of the body. 2. The empowerment of the participants, based on work done by two members of the PsF together with users of the mental health network in Rio de Janeiro entitled "Every dream well dreamed can one day become a reality". 3. The potentialization of the affections within the performance "The hug Project Brazil/Nepal " of Tania Alice.
\end{abstract}

Keywords: performance; relational art; clinic.

\section{Introdução}

A arte da performance se tornou tema corrente em diversas mídias, grupos, instituições de arte, universidades, comunidades. Muito se fala sobre performance, opiniões são proferidas, polêmicas são geradas. Porém, é importante destacar que quando se fala de performance, temos um amplo espectro de possibilidades dentro de um mesmo campo temático. A performance não é uma só, trata-se de uma arte extremamente heterogênea, pluralista, híbrida e com diversas modulações em termos de história e processos culturais.

Suas origens remontam às vanguardas do século XX, com destaque para alguns movimentos artísticos ocorridos em meados da década de 60, tais como body art, situacionismo, arte conceitual, dentre outras influências. Vemos um modo de produzir arte que não se encontra mais necessariamente atrelado a instituições tradicionalmente associadas a representação, tais como museus, teatros, galerias. Observa-se uma diluição de fronteiras entre linguagens artísticas e coloca-se em cheque o próprio lugar do artista, fazendo-nos repensar o distanciamento entre público e obra, e assim, mais do que espectador, as pessoas que se relacionam com os produtos e ações performáticas, podem ser também participantes e co-criadores dessas produções.

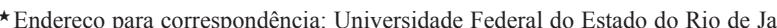
neiro, Escola de Teatro. Av. Pasteur, 296 - URCA. Rio de Janeiro, RJ - Brasil. CEP: 22290-040.E-mail: diogoreze@gmail.com, taniaalice@hotmail.com
A performance expande as noções que se tem sobre a "artisticidade" de uma ação. A ação em arte ganha uma outra amplitude, outros fôlegos, passa a construir outros territórios de apreciação. Muitas vezes vemos a performance causar choque, desconforto, desentendimento, estranhamento, e por conta disso, fazendo uma análise apressada, corre-se o risco de adjetivar a performance pejorativamente, desqualificá-la antes mesmo de tentar compreendê-la. Podemos compreender essas reações diante da performance por conta de um hermetismo inerente a alguns trabalhos, mas sobre isso, pode-se dizer que a performance está justamente rompendo com um campo de significação e representação, e tal como Gumbrecht (2010) propõe, a arte contemporânea se preocupa mais em produzir presença do que produzir sentido, e dessa maneira, os performers acabam sendo uma espécie de importantes e imprescindíveis "complicadores culturais" (FABIÃO, 2008).

A própria definição de performance se torna difícil de ser debatida, pois dizer que a performance "é", nos remete a um ideário modernista que categoriza e define esteticamente cada movimento de arte no decorrer da história (ALICE, 2013). Assim sendo, quando Austin propõe em seus estudos sobre linguagem, que cada fala realiza uma ação ao mesmo tempo em que é falada, a performance também se constitui como um processo que se faz em seu próprio percurso. Mais do que definir, pensar a performan- 
ce enquanto processo cartográfico que deve ser analisado no contágio de cada contexto em que se efetiva, nos parece ser o caminho mais potente para balizar essas discussões.

Por se tratar de uma arte que coloca em curto-circuito vários paradigmas artísticos, inclusive o de uma arte galerista e facilmente capturada por um modelo de circulação mercantilista e fetichizado, a performance também se forja através de uma estética imediatamente política, social, cultural. Um exemplo disso é o modo como a performance pode criar uma dramaturgia na cidade através de intervenções urbanas que jogam, criam, produzem e brincam com o que a própria cidade faz emergir em sua tessitura de acontecimentos. Vemos então um modo de produção em arte que coloca em relação direta corpo, estética e política, desinstitucionalizando a arte, quebrando a quarta parede dos museus, teatros e galerias, dissolvendo relações de poder entre artista e público, questionando a virtuose e a técnica.

Desse modo o performer não está interessado em simplesmente acumular inúmeras técnicas, formações, currículos, mas sim poder dar vazão a aquilo que ele já tem de força em si, e a performance se forja como o cultivo daquilo que o artista pode fazer exprimir de potente em si e em relação com os outros. Não há mais tanto interesse em explorar situações ficcionais, e começamos a ver trabalhos que se criam em contextos coletivos, grupais, étnicos, antropológicos, autobiográficos.

Os modos de ação em performance são amplos, variados, com uma liberdade de ação incalculável. Francis Alys, performer belga, convocou quinhentas pessoas de uma comunidade em Lima no Peru, para mover em dez centímetros uma duna de areia, sem motivo especifico, a não ser estabelecer uma rede de solidariedade. Tehching Hsieh, performer taiwanês, se trancou em uma cela em seu estúdio por um ano, ficando ali sem falar, sem ler, sem escrever, sem escutar música, sem ver televisão, contratando alguém para levar-lhe comida e um advogado para testemunhar a ação e guardar a chave. Esses são exemplos de como a performance, a partir de proposições simples e diretas, podem fazer disparar toda uma política de afetos extremamente intensa e complexa.

Fabião (2013) irá chamar de "programa performativo" o procedimento composicional do performer. Partindo do clássico texto de Deleuze e Guattari (1996), “28 de novembro de 1947 - Como criar para si um corpo sem órgãos", de onde o conceito de programa é o motor para a experimentação intensiva de algo, Fabião (2013, p. 4, grifo do autor) propõe que:

[O] programa é motor de experimentação porque a prática do programa cria corpo e relações entre corpos; deflagra negociações de pertencimento; ativa circulações afetivas impensáveis antes da formulação e execução do programa. Programa é motor de experimentação psicofísica e política. Ou, para citar palavra cara ao projeto político e teórico de Hanna Arendt, programas são iniciativas.

O programa então é o que enuncia a performance a partir de um plano composicional simples, direto e preciso, com ações previamente estipuladas e articuladas com clareza. Ou seja, trata-se de uma temporalidade muito diferente daquela do espetáculo, do ensaio, da coreografia ou da improvisação, onde o que importa é muito mais o exercício de uma presença aguçada naquilo que a performance evoca em termos de acontecimento. Para ilustrar o conceito de programa performativo Fabião (2013) cita o exemplo do performer americano Willian Pope L., que elaborou o seguinte programa para uma de suas performances: sobre a bandeira americana esticada na calçada, comer o Wall Street Journal ("Eating the Wall Street Journal", 1991). Temos aí um programa claro, conciso e direto, que dispara uma enunciação que simplesmente possibilita, norteia e move a ação.

\section{A dimensão relacional da performance}

Dada essa breve introdução sobre a performance, fica claro que estamos tratando de um dispositivo amplo e heterogêneo, com uma multiplicidade de dimensões que abarcam ações que interferem de diferentes modos junto as relações sociais. As performances passam por dimensões autobiográficas, relacionais, políticas, espirituais, ritualísticas, culturais, cênicas, dentre tantas outras, sendo que essas dimensões podem ou não se cruzarem e se efetivarem em concomitância.

Nos interessa aqui discorrer sobre a dimensão relacional da performance. E para isso torna-se imprescindível pensar as políticas de participação e relação entre público, obra, artista e espaços de fruição. Para ilustrar essas diferentes camadas relacionais, Pablo Helguera (2011), artista, performer e diretor dos programas acadêmicos do MoMA em New York, pode nos ajudar a disparar algumas discussões. Ele propõe quatro tipos de participação na relação público-obra:

1. Participação Nominal: o espectador participa de maneira passiva da obra, vendo os quadros ou assistindo a uma peça, o que já requer um tipo de participação.

2. Participação Direcionada: o espectador executa uma tarefa simples, decidida anteriormente pelo artista. Exemplo: a obra "Wish tree" (1996) de Yoko Ono, onde o participante escreve um desejo em um pedaço de papel e o pendura em uma árvore.

3. Participação Criativa: o participante produz conteúdos para compor o trabalho dentro de uma estrutura previamente estabelecida pelo artista. Exemplo: feiras de trocas performativas, onde é estabelecido que não haverá circulação de dinheiro, mas cada um é convidado a propor e trocar aquilo que deseja, tal como o coletivo "Quandonde - intervenções urbanas" realiza em Curitiba (PR).

4. Participação Colaborativa: O participante colabora no desenvolvimento da estrutura e do conteúdo do trabalho em colaboração e diálogo direto com o artista, como é o caso do trabalho do performer Marcelo Asth, que trabalha com pessoas idosas dentro do projeto "Performanciã", no qual os participantes elaboram suas ações. 
Helguera problematiza os modos de participação lançando alguns questionamentos: Eu participo de uma obra simplesmente entrando em uma galeria de arte? Ou eu só participo quando eu ativamente me envolvo na produção de um trabalho? São questões complexas, e a proposta de pensar essas quatro camadas de participação de Helguera, tal como ele pontua, devem ser vistas sem hierarquia em termos de menos ou mais bem-sucedida ao afetar o público. Ele aponta que essas distinções servem apenas para ajudar a clarear toda uma ampla gama de possibilidades que envolve a participação em arte.

Porém é sempre importante problematizar esses limiares que fazem com que as políticas de participação em arte se modulem, assim como questionar quais são os modos de ação em arte que ainda mantém uma certa hierarquização e distanciamento entre artista e público e, visando problematizar um pouco esses limiares e experimentando borrar essas fronteiras, iremos discutir o conceito de arte relacional.

Nicolas Bourriaud (1998), em seu livro Estética relacional, propõe que a possibilidade de uma arte relacional, que tem como horizonte a esfera das relações e interações humanas e seu contexto social, faz com que ocorra uma inversão radical dos objetivos estéticos, culturais e políticos propostos pela arte moderna, justamente por não afirmar a arte a partir de um espaço simbólico autônomo e privado. Já não se considera a obra contemporânea a partir de um espaço a ser percorrido, e sim como uma duração a ser experimentada em uma abertura de sensações ilimitadas.

Bourriaud relembra o termo "interstício" usado por Karl Marx e que designa comunidades de troca que escapam ao quadro da economia capitalista por não obedecerem à lei do lucro. $\mathrm{O}$ interstício seria então um espaço das relações humanas que, mesmo mais ou menos inseridas no sistema global, fazem passar outras possibilidades de trocas além das trocas capturadas e vigentes nesse sistema. Uma ação em arte relacional que habita esse interstício cria espaços de liberdade, gerando durações com ritmos contrários ao das durações que ordenam nossas vidas, favorecendo intercâmbios sensíveis diferentes das zonas de comunicação das grandes narrativas de poder e controle.

Desse modo, vemos uma possibilidade de trabalho em arte onde mais importante que a produção de uma obra final, será o que acontece no âmbito intersticial, ou mais precisamente, no relacional, no que há de potente entre as pessoas envolvidas nessa produção. Podemos dizer que a arte relacional se configura então como um dispositivo de produção de relações entre as pessoas, e entrando nessa camada relacional, a produção se torna mais importante que o produto, a troca de afetos e a partilha de um campo sensível entre as pessoas se torna a força motriz de produção em arte.

Isso quebra radicalmente um distanciamento entre artista e público apreciador, e talvez o artista atue aqui - usando um termo caro para os trabalhos finais de Hélio Oiticica e Lygia Clark - como um propositor muito mais do que um autor de determinada obra, trata-se então da proposição de acontecimentos de sociabilidade, ou objetos que produzem sociabilidade, enfocando um primado da relação muito mais do que do produto estético pronto e acabado.

Porém a criação de relações se situa dentro de uma esfera extremamente complexa, e por isso, ainda assim corre-se o perigo de reiterar relações que reproduzem formas de subjetividade capturadas pelas estruturas de poder. Claire Bishop (2004), em "Antagonism and relational aesthetics", critica as práticas relacionais que não empoderam os participantes mas reiteram relações de poder ou de consumo já presentes na sociedade. Bélenguer e Melendo (2012) em "El presente de la Estética Relacional: hacia una crítica de la crítica" também ressaltam a fragilidade de algumas práticas sociais, quando estas não estabelecem relações críticas diante das relações de poder vigentes.

Diante dessa complexa rede de afetos que envolvem as relações entre as pessoas e as coisas, torna-se imprescindível pensar de maneira prática quais seriam as possibilidades de construção dessas propostas relacionais, por isso lançaremos mão do trabalho realizado na plataforma de performances "Performers sem Fronteiras".

\section{Performance de Arte Relacional como prática de Cura (PARC) e a plataforma "Performers sem Fronteiras" (PsF)}

A partir dessas reflexões a respeito das possíveis relações e sociabilidades disparadas pela performance, focamos aqui em um recorte específico que diz respeito as práticas de performance que possuem algum grau ou atravessamento clínico/terapêutico. Denominamos estas experiências fronteiriças de PARC (Performances de Arte Relacional como prática de Cura), conceito desenvolvido por Tania Alice (2015) e operador para auxiliar o entendimento destas experiências que abordam a performance como uma possível prática de cura por meio de dispositivos relacionais acionados por um performer/terapeuta.

A ideia aqui é pensar as PARC naquilo que há de atravessamentos clínicos e terapêuticos na performance. Não queremos aqui simplesmente atrelar o viés clínico como algo inerente a performance, mas sim pensar quais as possibilidades clínicas podem ser ativadas na efetivação de dispositivos de arte relacional. Nesse sentido, é importante destacar a discussão sobre transdisciplinaridade da clínica proposta por Passos e Barros (2000), onde vemos uma problematização em cima das disciplinas que marcam fronteiras rígidas nas definições de seus objetivos de pesquisa e ação. Ao analisar o esforço realizado nas últimas décadas para flexibilizar tais fronteiras, vemos que essa flexibilização se dá em diferentes movimentos:

O movimento de disciplinas que se somam na tarefa de dar conta de um objeto que, pela sua natureza multifacetada, exigiria diferentes olhares (multidisciplinaridade), ou, de outra forma, o movimento de criação de uma zona de interseção entre elas, para a qual um objeto específico seria designado (interdisciplinaridade). Mas o que vemos como efeito, seja da multidisciplinaridade, seja da interdisciplinaridade, é a manutenção das fronteiras disciplinares, dos objetos e, especialmente, dos sujeitos desses saberes (PASSOS; BARROS, 2000, p. 74). 
Nesse sentido, a produção de uma transdisciplinaridade da clínica seria realizada em um plano onde sujeito e objeto simultaneamente se adviriam, ressaltando o primado da relação entre esses termos, e assim seria possível problematizar de fato os limites de cada disciplina em seus pontos de congelamento e universalidade, tornando essas fronteiras instáveis e fazendo passar sempre o que emerge enquanto singularidade, ou o que produz uma diferença, nessa política dos encontros entre os termos de uma relação. E aqui nossa discussão ganha outro corpo, pois borrar as fronteiras entre arte, performance, clínica, terapias, práticas de cura, passa a ser nosso principal mote de trabalho.

Além disso, outro conceito importante de ser destacado nessa discussão sobre as PARC é o conceito de cura, pois também não é objetivo nosso dizer em tom salvacionista que a performance promove por si só a cura de traumas ou de outros sintomas em trabalhos realizados. Talvez pensar o conceito de cura a partir de práticas de saúde tais como a Medicina Tradicional Chinesa, a Medicina Ayurvedica ou o Yoga, que apontam a cura muito mais como toda e qualquer prática que cultiva uma saúde e alimenta aquilo que o ser humano possui de potente, pode nos servir muito mais de intercessor do que o conceito senso comum de cura como mera cessação de sintomas. Ou seja, em nossos trabalhos vemos o trabalho de cura muito mais como o cultivo de uma saúde, ou o cultivo de práticas que podem gerar saúde por contágio a partir da própria experiência relacional.

Podemos então agora ilustrar melhor esse conceito de PARC, e para isso partiremos do trabalho da plataforma Performers sem Fronteiras, uma plataforma composta por performers/interventores que possuem o interesse mútuo na elaboração de ações que atuem na zona de contaminação entre projetos artísticos e sociais, clínico/terapêuticos, ecológicos e espirituais. Ao unir artistas que pesquisam e realizam intervenções artísticas participativas dentro do conceito de PARC, o Performers sem Fronteiras (PsF) se propõe a atuar em situações onde haja abertura a ações colaborativas de trabalho com base no respeito à diferença e a identidade cultural, propondo intervenções artísticas que atuam de forma construtiva na gestão individual ou coletiva de traumas e na construção de processos de paz. Fazem parte do espectro de atuação do PsF situações geradoras de trauma como conflitos armados, catástrofes naturais, ambientais e sociais, bem como situações do dia-a-dia em ações de cultivo e promoção de saúde. Dentro da plataforma, os artistas elaboram suas propostas de ação junto a colaboradores inseridos dentro das realidades visadas, estabelecendo conexões e parcerias pelo fortalecimento do pensamento e da ação coletiva, dentro de um processo que, mergulhando na experiência, busca agenciar sujeito e objeto, teoria e prática dentro de um mesmo plano de co-emergência.

Atualmente a plataforma se reúne de forma presencial quinzenalmente na casa de uma das integrantes do grupo, e se abre periodicamente para novos participantes. O processo de construção desta plataforma tem se desenvolvido na linha de um pensamento coletivo, ecosófico, relacional, construtivista, transdisciplinar, complexo e sistêmico a partir de procedimentos cartográficos e somáticos, que visam a: estabelecer cartografias do que emerge "no" e "a partir do" corpo; a pesquisa de procedimentos somático-performativos de atuação no mundo; o estudo e a mobilização dos recursos oferecidos pela comunicação como mediadora relacional; a reflexão sobre o papel do artista em contextos de emergência; a reflexão sobre a formação possível para este artista. O espaço de encontro se apresenta como um espaço para instrumentalizações cruzadas e potencializações mútuas, dentro da construção de um universo seguro para a troca de experiências, questões e dúvidas, o que inclusive facilita os processos de orientação artística-interventiva individual de cada membro do grupo.

Neste momento a plataforma é composta de forma permanente por Diego Baffi (ator - intervenção e palhaçaria - dançarino, professor da Faculdade de Artes do Paraná/ Universidade Estadual do Paraná (FAP/UNESPAR) e doutorando da Universidade Federal do Estado do Rio de Janeiro (UNIRIO), Diogo Rezende (performer, dançarino, terapeuta e Doutorando da UNIRIO), Marcelo Asth (performer, idealizador do projeto Performanciã e Doutorando da UNIRIO), Gilson Moraes Motta (diretor teatral e professor da Escola de Belas-Artes da Universidade Federal do Rio de Janeiro (UFRJ), Fernanda Paixão (palhaça e pesquisadora formada pela UNIRIO) e Tania Alice (performer, terapeuta de experiência somática, professora coordenadora deste projeto de pesquisa da UNIRIO), Laurie Freychet (artista e terapeuta de Reiki), Gabriel José e Augusto Semensatti (monitores da disciplina de Performance ministrada por Tania Alice na UNIRIO).

\section{Ações recentes do Performers sem Fronteiras}

Neste ponto, mais do que realizar uma lista das ações performáticas realizadas pela plataforma, pretendemos tomar como ponto de partida três eixos transversais das ações realizadas: o movimento livre, a potencialização dos afetos nas artes relacionais e o empoderamento dos participantes em ações de arte relacional.

\section{1 - O movimento livre}

Um dos eixos comuns das ações realizadas pela plataforma consiste em propor espaços onde a escuta de si e do corpo e a expressão do que dele emerge se constitui como uma pratica reguladora. A primeira experiência neste sentido foi o desenvolvimento da performance "Dança livre para todos", realizada no "Festival Internacional da Republica Dominicana" em 2013, no "Festival Internacional 1000 em 1" (2013) no Rio de Janeiro e em seguida em parceria com Diego Baffi, de Curitiba, que vinha realizando a performance "Espaço disponível para dançar" na "Mostra p.Arte" de Curitiba com curadoria de Fernando Ribeiro. Nesta performance, é oferecida primeiro uma oficina e depois é realizada uma performance de dança livre em espaços públicos, onde apenas é disponibilizado um espaço livre e aberto para a dança, deixando o convite a qualquer pessoa interessada a poder partilhar a experiência de dançar juntos. 
Inspirada na dança contemporânea dos 5 Rhythms de Gabrielle Roth, durante duas horas, conduzidos por músicas que marcam esses 5 ritmos, o corpo passa por um processo de regulação através de preparação, ativação e integração. Não há regras para essa dança, senão escutar o corpo, não se preocupar com o modo como dança, abaixar os filtros de julgamento e adjetivação. "Dançar feio e babar muito" é uma espécie de lema motivador para esse trabalho. A dança nesse sentido se constitui como uma meditação em movimento, durante a qual o corpo pode se expressar de forma espontânea. Conforme aponta Gabrielle Roth (2016, online, tradução nossa), criadora dos 5Rhythms:

Quando praticamos os 5Rhythms, aprendemos a expressar emoções de agressividade, e vulnerabilidade, dificuldades e ansiedade de forma criativa. A prática nos reconecta com os ciclos de nascimento e morte e nos conduz à humanidade e ao espírito de todos os seres vivos. [...] Os 5Rhythms transcendem a dança. O movimento é a medicina, a meditação e a metáfora. Juntos, deixamos as mentiras para trás, deixamos as máscaras caírem e dançamos até desaparecer. ${ }^{1}$

A junção dessa pratica com os recursos do $\mathrm{SE}^{2}$ foi analisada por Tania Alice e por Diego Baffi (2016) em "Traga seus problemas para a arte! Performances de arte relacional como cura", que mostra como as diferentes fases dos 5Rhythms (flow, staccato, caos, lírico e a quietude) correspondem a curva do sistema nervoso em processo de regulação. Esse trabalho foi realizado em outras ocasiões por Tania Alice e seguiu acontecendo de maneira semanal com um grupo sempre aberto e gratuito na Unirio entre os anos de 2014 e 2016.

\section{2 - A potencialização dos afetos nas artes relacionais}

A performance "Correio de abraços Brasil / Nepal" foi idealizada por Tania Alice após os terremotos que ocorreram no Nepal nos dias 25 de abril e 2 de maio de 2015. Essa ação se deu a partir de um sentimento de impotência diante dos acontecimentos e das alarmantes notícias de que doações internacionais de ajuda para o país estavam sendo desviadas pelo governo nepalês. Nesse sentido ressoava na performer a seguinte questão: $\mathrm{O}$ que era possível de ser feito e que manifestasse essa solidariedade vista nas doações internacionais, e que ao mesmo tempo, não fosse passível de desvio e corrupção por parte do governo nepalês?

"Escolha um abraço de 5, 10 ou 15 minutos. Venha me entregar o seu abraço. Dia 5 de julho, estarei embarcando para o Nepal e irei entregar pessoalmente o abraço para o destinatário que você escolheu ou visualizou durante o abraço". Estes foram os dizeres de um cartaz que a performer carregou com ela por 5 semanas seguidas. Sentada em praças, salas de espera, transportes públicos, em festivais e em reuniões diversas, dia após dia, ela foi coletando esses longos abraços. Após cada abraço, quem tinha entregue o abraço podia escolher a pessoa a quem

\footnotetext{
${ }^{1}$ Para mais informações sobre os 5rhythms, ver Roth (1997).

${ }^{2}$ Somatic Experiencing (Experiência Somática), técnica somática para a resolução e cura de traumas, criada e fundamentada por Peter Levine $(1999,2005)$ e da qual a performer Tania Alice se utiliza em algumas de suas ações em performance.
}

o abraço era destinado. Às vezes, podia ser uma visão que ela tinha tido durante o abraço ("eu vi um menino de sete anos com roupa verde"), às vezes era uma escolha racional ("quero que meu abraço seja entregue para uma senhora de 70 anos, uma criança, uma mãe, etc.). Desta forma, durante o mês de maio e junho de 2015, a performer coletou 605 minutos de abraços de brasileiros para 124 destinatários moradores do Nepal. No dia 5 de julho, junto a outros profissionais da saúde, terapeutas e artistas, Tania Alice embarcou para o Nepal, com as fotos impressas dos remetentes dentro de envelopes para os seus destinatários. No Nepal, com a ajuda de um artista/ tradutor local, ela foi a pé, de ônibus, van ou scooter procurar os 124 destinatários. Encontrou as crianças, grupos, idosos, adultos nas mais diversas regiões do país e em diversas situações sócio-econômicas, sanitárias e de saúde. Alguns abraços também foram destinados a plantas e animais. A cada abraço entregue, foi enviada uma foto para o remetente confirmando a entrega. A performer voltou para o Brasil em 5 de agosto de 2015. Os 124 abraços tinham chegado aos seus destinatários. Essa performance está registrada em um jogo de memórias feito a partir dos pares de abraços entre Brasil e Nepal e que foi lançado em dezembro de 2016 no Rio de Janeiro.

\section{3 - O empoderamento dos participantes em ações de arte relacional}

Durante o segundo semestre de 2015, Diogo Rezende e Tania Alice, em articulação com a terapeuta ocupacional Roberta Carvalho do Centro Psiquiátrico do Rio de Janeiro (CPRJ), participaram regularmente das oficinas de criação em arte e corpo facilitada pela própria Roberta junto aos usuários deste serviço de saúde mental.

A partir deste trabalho, foi sendo articulada junto a esses usuários a criação de uma performance relacional construída de maneira coletiva e que posteriormente seria apresentada no $10^{\circ}$ Seminário de Medicina Social do Instituto de Medicina Social da Universidade do Estado do Rio de Janeiro (UERJ).

Os usuários do CPRJ que frequentavam este grupo possuíam longas histórias de tratamento em saúde mental, alguns deles com longos períodos de internação e todos eles com certa cronicidade em seus tratamentos. Dessa maneira foi sendo realizado um trabalho de vinculação a partir do que os próprios usuários manifestavam de interesse nas propostas artísticas trabalhadas no grupo facilitado por Roberta. E após participar semanalmente desses grupos, Diogo e Tania propuseram a criação de uma performance coletiva realizada pelos próprios usuários. O grupo era grande, com cerca de 25 usuários, e desses, quatro deles manifestaram interesse em construir uma performance coletiva.

A partir daí começamos um trabalho semanal de criação com esses quatro usuários, clareando a proposta de realizar essa ação para os profissionais de saúde participantes do $10^{\circ}$ Seminário de Medicina Social da UERJ, o que os deixou muito motivados. Em nossos encontros cada um

Fractal, Rev. Psicol., v. 29 - n. 2, p. 196-202, 2017 
dos quatro foi manifestando aquilo que mais gostavam de fazer e o que mais gostariam de compartilhar com os profissionais de saúde que participariam do evento na UERJ.

No final chegamos a ação coletiva "Todo sonho bem sonhado pode um dia virar realidade", nome criado por um dos usuários para a performance onde cada um deles, durante uma tarde inteira do evento na UERJ, pôde partilhar com os profissionais de saúde presentes no evento, aquilo que mais gostavam de fazer: uma mesa de criação conjunta de poesias, um bate-papo sobre a situação política do país, uma mesa sobre dispositivos eletrônicos e informática e um convite a lavar louças com uma boa conversa para passar o tempo.

Os desafios do trabalho em saúde mental são imensuráveis, e a desinstitucionalização é algo a ser feito cotidianamente, mas ali, durante toda a tarde de um evento acadêmico com palestras e apresentações de trabalhos, uma outra política de trocas entre profissionais de saúde e usuários da saúde mental pôde ser estabelecida. E assim, o protagonismo dessa performance é assumido por essa complexa, rica e, muitas vezes sofrida, paisagem subjetiva desses quatro performers.

\section{Conclusão}

Muito além do tão enfatizado "corpo do performer", "corpo do dançarino" e "corpo do artista", o espaçotempo expandido pela somático-performatividade transforma a virtualidade coerciva (mascarada em realidade de consumo) em realidade transgressiva e somática (através da virtualidade estética), enfatizando a senso-percepção e a conexão com (n)o todo (FERNANDES, 2014, p. 4).

Ciane Fernandes vem trabalhando no Programa de Pós-Graduação em Artes Cênicas da Universidade Federal da Bahia a proposta de uma pesquisa somático-performativa (PSP), e com essa proposta temos um tipo de pesquisa onde a prática não é tomada mais como um objeto de estudo, ao invés disso a prática é em si mesma o método de pesquisa, ou seja, temos um tipo de pesquisa onde a prática se torna o eixo principal e organizador da experiência de pesquisa. Porém, para além desse viés prático, há também o viés somático dessa proposta de pesquisa. Trata-se de tomar uma concepção somática dessas práticas, uma concepção somática que tem como eixo a experiência vivida como um todo (pulsações, sensações, imagens), bem como todas as conexões que se faz entre interno e externo, mobilidade e estabilidade etc. Além de uma integração dos níveis físicos, emocionais, cognitivos, culturais, espirituais e sociais (FERNANDES, 2014).

Ciane Fernandes ressalta, porém, que não se trata de necessariamente aplicar técnicas de educação somática e nem de estudar performance para ser considerada uma PSP, pois o fundamental é que se tome a corporeidade como um todo somático, autônomo e relacional. $\mathrm{O}$ modus operandi desse tipo de pesquisa tomará as conexões somáticas criativas como seu eixo norteador. Temos aí uma concepção ampliada acerca de uma experiência somática, temos uma perspectiva somático-performativa que leva a experiência de pesquisa para a amplitude da prática vivida no/com o todo do espaço-tempo.
Tendo em vista os trabalhos da plataforma PsF aqui expostos, percebemos que de maneira geral, há três conceitos atravessadores comuns entre todos eles, a saber: a clínica, o somático e a performatividade. A partir desses três conceitos, Diogo Rezende vem elaborando em seu processo de doutoramento em Artes Cênicas na UNIRIO, o conceito de clínica somático-performativa. Trata-se de um trabalho prático e conceitual que alia a transdisciplinaridade da clínica com algumas perspectivas de educação somática e o paradigma performativo na arte contemporânea para pensar o corpo e as relações entre corpos suscitadas por diferentes trabalhos de arte relacional.

No contágio desses trabalhos, é importante destacar o artigo indefinido "uma". Tratamos aqui de uma clínica somático-performativa, pois não se trata de uma proposta ou modelo clínico definido e acabado. Trata-se de uma proposta experimental que se faz em seu próprio processo de acontecimento e nesse sentido podemos dizer que os trabalhos empreendidos pela plataforma PsF nos coloca no lugar do cultivo e da promoção de uma saúde, uma saúde que seja amparada por perspectivas relacionais e que fomentem a sociabilidade e as partilhas sensíveis entre as pessoas.

\section{Referências}

ALICE, T. Diluição das Fronteiras entre linguagens artísticas: a performance como (r)evolução dos afetos. Catálogo Nacional, [S.1.], 2013. Disponível em: <http://taniaalice.com/wp-content/ uploads/2012/11/palco2014_Artigo_Tania.pdf>. Acesso em: 22 mar. 2017.

ALICE, T. PARC (Performances de Arte Relacional como Cura): performance e Somatic Experiencing. Revista Brasileira de Estudos da Presença, Porto Alegre, v. 5, n. 2, p. 396-412, maio/ago. 2015. Cross ${ }^{\text {Ref. }}$

ALICE, T.; BAFFI,D. E. Traga seus problemas para a arte! Performances de arte relacional como cura. In: ALICE, T. (Org.). Performance como Revolução dos Afetos. São Paulo: Annablume, 2016. p. 177-194.

BELENGUER, M. C.; MELENDO, M. J. El presente de la estética relacional: hacia una crítica de la crítica. Calle 14: Revista de investigacion en el campo del arte, Colômbia, v. 6, n. 8, p. 88-100, 2012. Disponível em: <http://revistas.udistrital. edu.co/ojs/index.php/c14/article/view/3789>. Acesso em: 23 mar. 2017.

BISHOP, C. Antagonism and Relational Aesthetics. October, New York, n. 110, p. 51-79, 2004. Disponível em: $\quad<$ http://academicworks.cuny.edu/cgi/viewcontent. cgi? article $=1095 \&$ context=gc_pubs $>$. Aceito em: 21 mar. 2017.

BOURRIAUD, N. Esthétique relationnelle. Paris: Les Presses du Réel, 1998.

DELEUZE, G.; GUATTARI, F. 28 de novembro de 1947 - Como criar para si um corpo sem órgãos. In: _. Mil platôs: capitalismo e esquizofrenia. São Paulo: Editora 34, 1996. v. 3, p. 9-30.

FABIÃO, E. Performance e teatro: poéticas e políticas da cena contemporânea. Sala Preta, São Paulo, v. 8, p. 235-246, nov. 2008. Cross ${ }^{\text {Ref. }}$ 
FABIÃO, E. Programa performativo: o corpo-em-experiência. Ilinx - Revista do LUME, Campinas, n. 4, p. 1-11, dez. 2013. Disponível em: <http://www.cocen.unicamp.br/revistadigital/ index.php/lume/article/view/276/256>. Acesso em: 12 mar. 2017.

FERNANDES, C. O avesso da travessia: o espaçotempo somático-performativo. Performatus, [online], ano 2, n. 9, mar. 2014. Disponível em: <http://performatus.net/wp-content/ uploads/2014/03/O-Avesso-da-Travessia-«-Performatus.pdf $>$. Acesso em: 20 mar. 2017.

GUMBRECHT, H. U. Produção de presença: o que o sentido não consegue transmitir. Rio de Janeiro: PUC Rio, 2010.

HELGUERA, P. Education for socially engaged Art. New York: Jorge Pinto Books, 2011.

LEVINE, P. O despertar do tigre. São Paulo: Summus, 1999.

LEVINE, P. Uma voz sem palavras. São Paulo: Summus, 2005.

PASSOS, E.; BARROS, R. D. B. A construção do plano da clínica e o conceito de transdisciplinaridade. Psicologia: Teoria e Pesquisa, Brasília, v. 16, n. 1, p. 71-79, jan./abr. 2000. Cross ${ }^{\text {Ref }}$

PURVES, T. What we want is free - generosity and exchange in recent art. New York:State University of New York, 2005.

ROTH, G. Os ritmos da alma: o movimento como prática espiritual. Tradução de Newton Roberval Eichemberg. São Paulo: Cultrix, 1997.

ROTH, G. Gabrielle Roth's 5Rhythms. In: 5RHYTHMS. 2016. Disponível em: <https://www.5rhythms.com/gabrielle-roths5rhythms/>. Acesso em: 20 mar. 2017.

Recebido em: 4 de abril de 2017

Aceito em: 30 de junho de 2017 